\title{
Real-Time Data Center Design using Firebase: A Case Study of Sales System Design
}

\author{
Harson Kapoh \\ Dept. of Information Technology \\ State Polytechnic of Manado, \\ Indonesia
}

\author{
Olga E.Melo \\ Dept. of Information Technology \\ State Polytechnic of Manado, \\ Indonesia \\ Anritsu Polii \\ Dept. of Information Technology \\ State Polytechnic of Manado, \\ Indonesia
}

\author{
Anthon Arie Kimbal \\ Dept. of Information Technology \\ State Polytechnic of Manado, \\ Indonesia
}

\begin{abstract}
There is a need for a system that can connect producers and consumers of coconut flour in sharing information and making transactions, therefore we make this study try to design an efficient and effective communication platform for the coconut flour industry. The high demand for coconut flour from consumers and their remote locations has triggered the development of a real-time system that can solve communication problems between them.

This design involves diagrams such as usecase diagrams, flowchart diagrams and activity diagrams for centralized realtime data logic. The result is a realtime database using Firebase as a centralized data implementation and because of the ease with which the cloud system is connected to Android on the user's smartphone side to place orders.
\end{abstract}

\section{General Terms}

Firebase Database

\section{Keywords}

Design, real-time, firebase

\section{INTRODUCTION}

Demand for coconut flour for domestic and export needs is very high. During the Covid 19 pandemic the export demand for coconut flour was still high for the industry in North Sulawesi, in the first quarter of 2020468.88 tonnes had been exported to China (Desperindag Sulut).

To connect and help increase consumer confidence in the coconut flour industry, an order and sales system is needed that can make the process more efficient and effective. Therefore, an alternative communication between the coconut flour industry and consumers is needed.

In this article, to anticipate the demand for coconut flour that continues to exist and tends to increase, it is deemed necessary to innovate by taking a technological approach, namely information technology[1].

Optimizing the sales process of coconut flour in the base to improve service to consumers and increase trust[2]. The optimization in question is in the sales process by carrying out a real-time process so that orders are well identified and validated.

Firebase database is a tool that can be used to realize an optimal sales process because Firebase is a real-time based database and can be connected to Android and the web well[3].

Android, in this case the smartphone, will be the client that will be used for ordering coconut flour. Real-time data center design using firebase as a case study of sales system design is expected to be the basis for real-time sales development.

\section{TEORI}

\subsection{Firebase}

Realtime database services for various existing platforms such as mobile and web applications are needed[3]. Firebase is a realtime database which in the process includes a database without using SQL or No SQL[3]. Firebase is hosted or hosted on the cloud so that applications from various platforms can interact in real time.

Firebase is a realtime database that implements storage, hosting and authentication functions[3][4].

Storage on this system uses the Firebase realtime database for validation to identify users accessing the application. In addition, firebase is used to store order data which will be accessed by the admin so that the order process can be managed more efficiently.

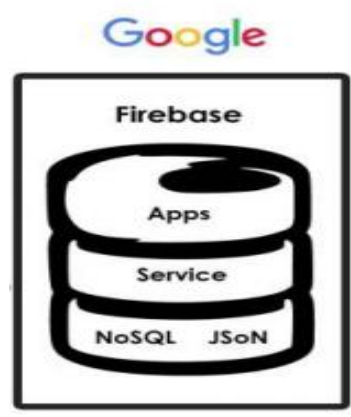

Fig 1: Struktur firebase

\subsection{Real-time}

Changing data in the database and subsequently sending data to all connected devices in milliseconds is a good real-time concept. In the Firebase Realtime database, real-time data processing occurs because the data synchronization process is carried out continuously when data changes occur. 


\subsection{Centralized Data}

Centralized data is one of the topologies in data storage in the concept of a database as a centralized storage system that is integrated as needed[4].

\section{RESULTS AND DISCUSSION}

\subsection{Architecture System}

The results of designing a data center using firebase to make it easier for system development and database implementation. The real-time architecture implementation with firebase produces a cloud-based database system.

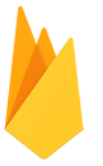

Realtime

Firebase

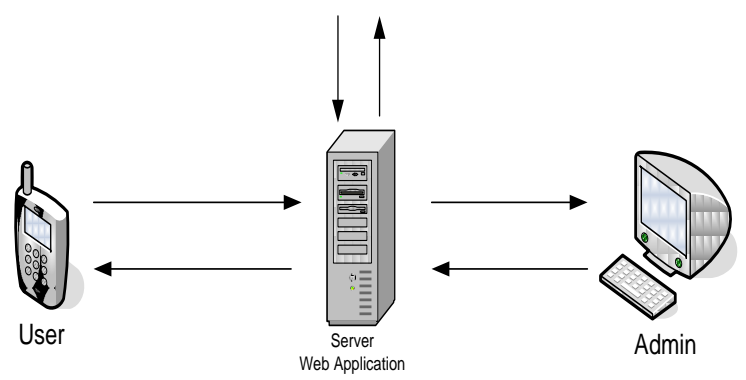

Fig 2: Architecture System

Figure 2.is a system architecture developed for the design of a centralized data system using Firebase with an Android system on the client side and a web system on the admin side.

Users can communicate with the admin through the firebase database server.

\subsection{Flowchart}

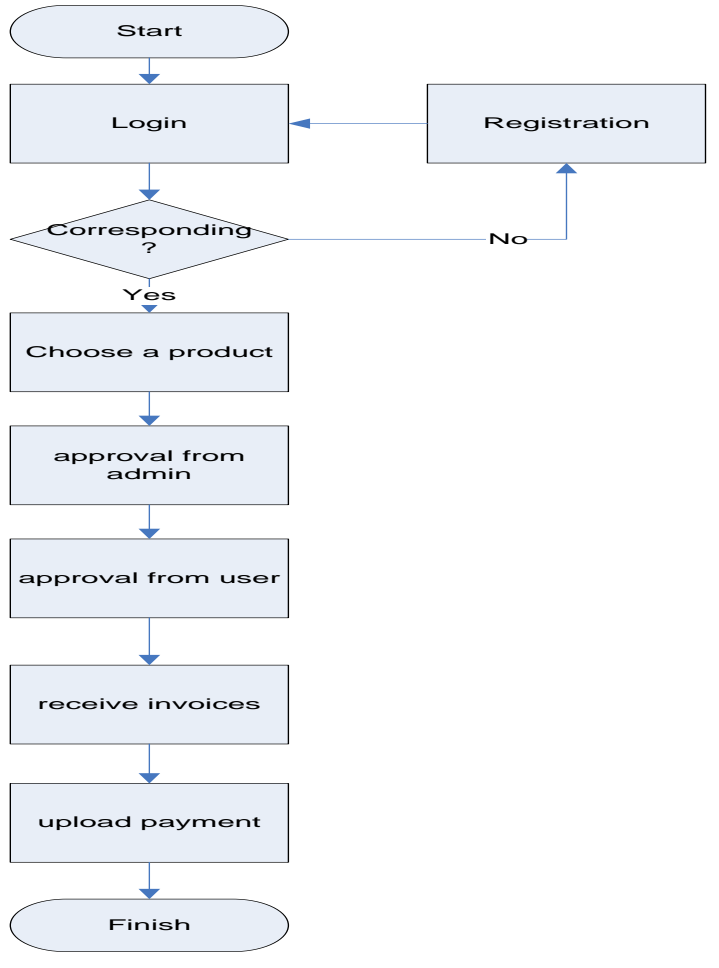

Fig 3: Client-side flowchart

\subsection{Use Case Diagram}

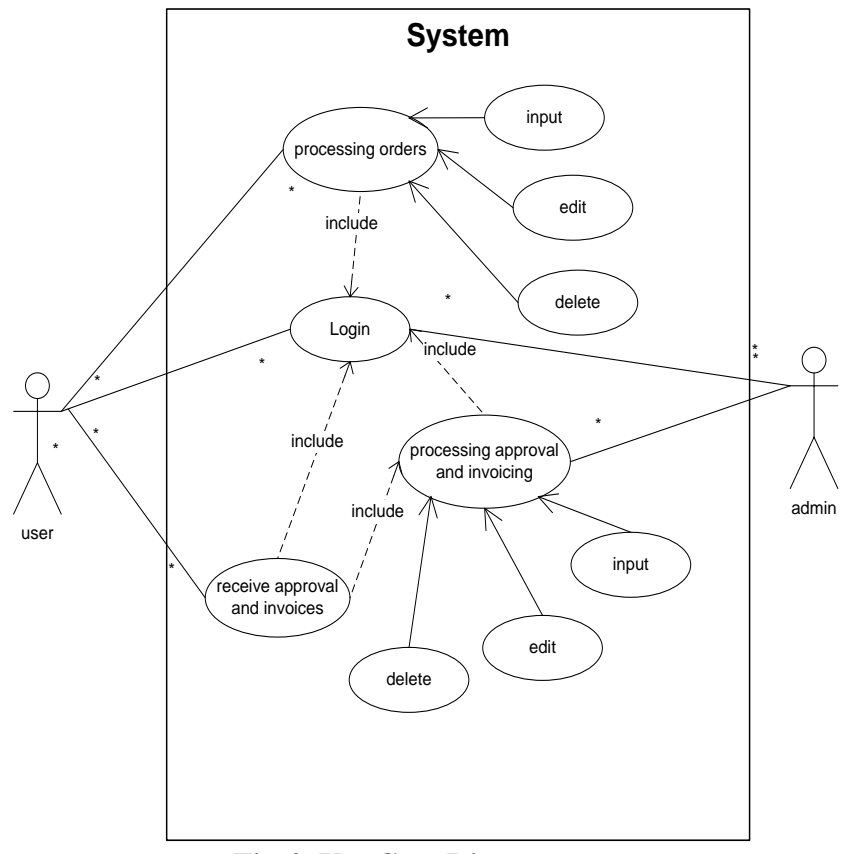

Fig 4: Use Case Diagram

Figure 4. is a use case diagram which is a functional design of the system which illustrates the existence of 2 actors, namely user and admin.

\subsection{Activity Diagram}

Figure 5.is an activity diagram used to design activities that may exist on the user, system and admin sides according to implementation needs.

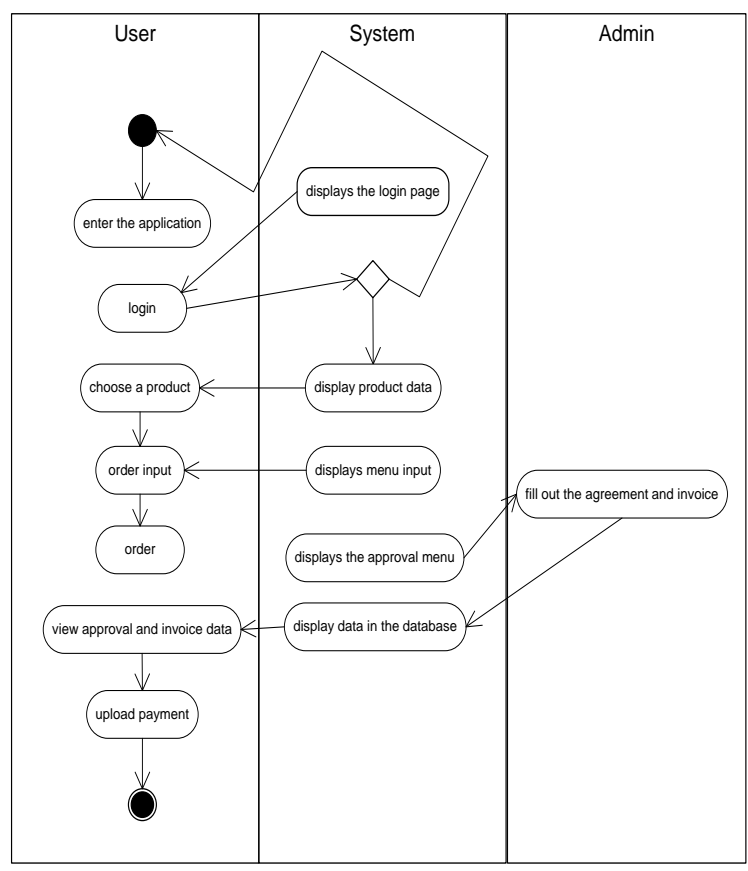

Fig 5: Activity Diagram

\subsection{Interface Design}




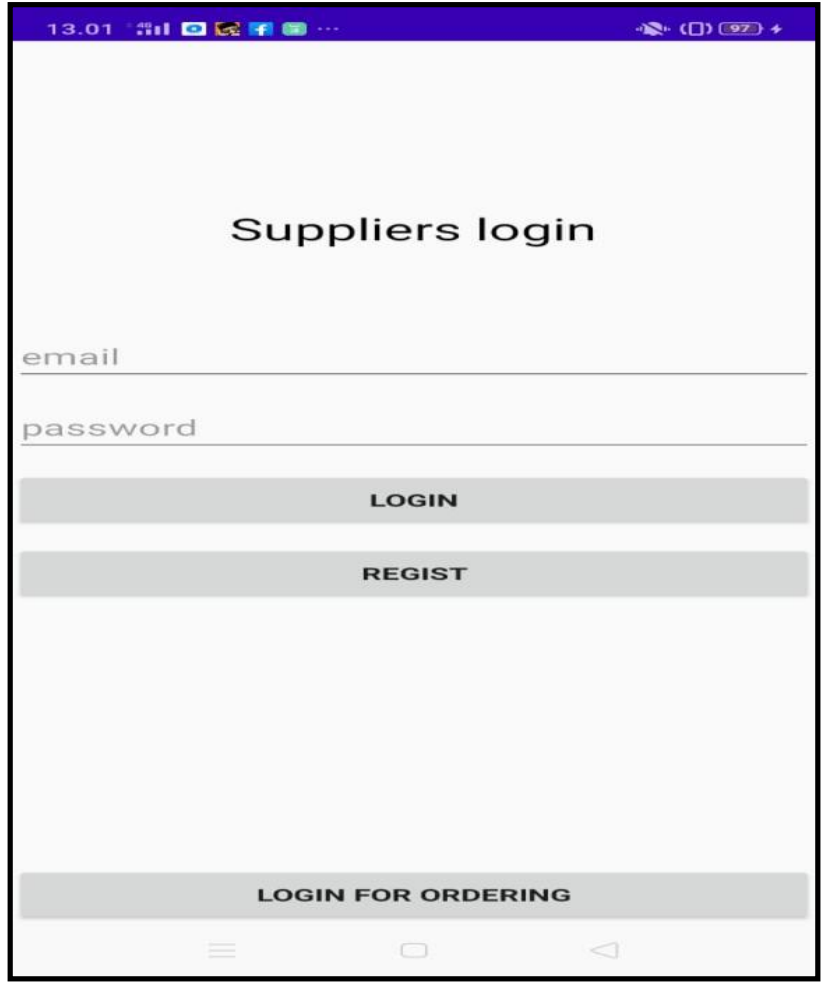

Fig 6: Login Interface Design

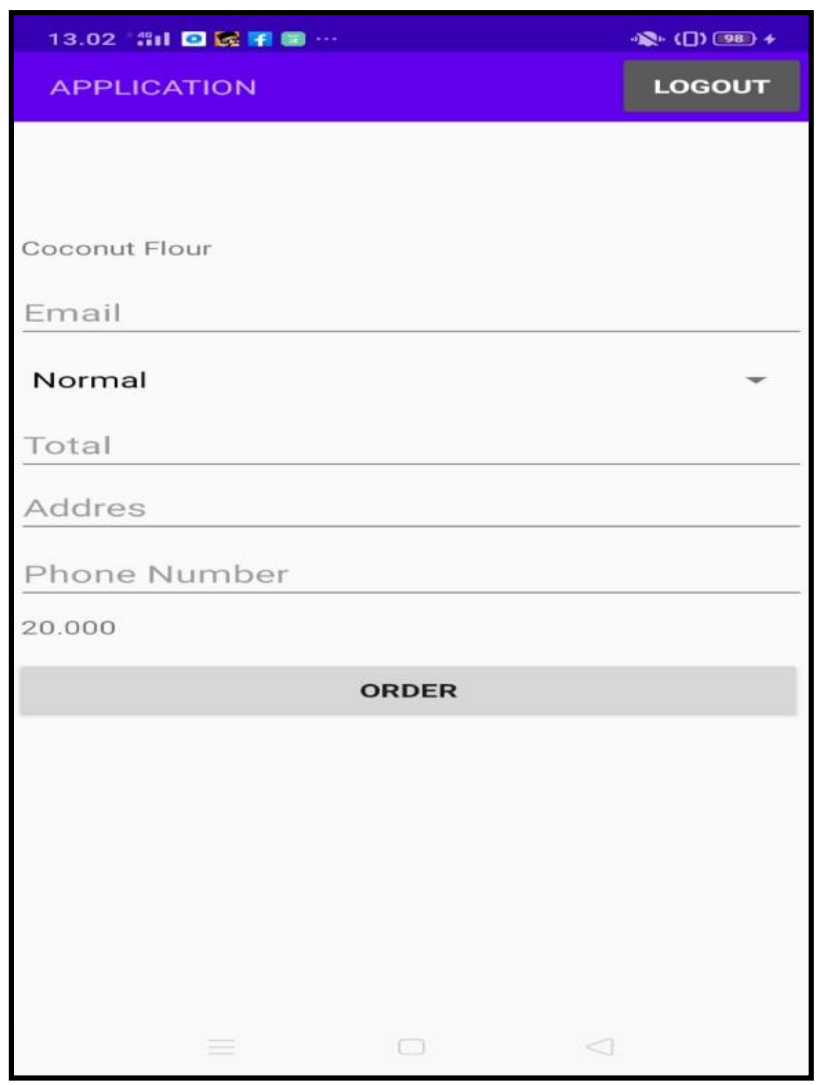

Fig 7: Ordering Interface Design

\subsection{Coding}

An example of the coding used so that Android can access the Firebase database.

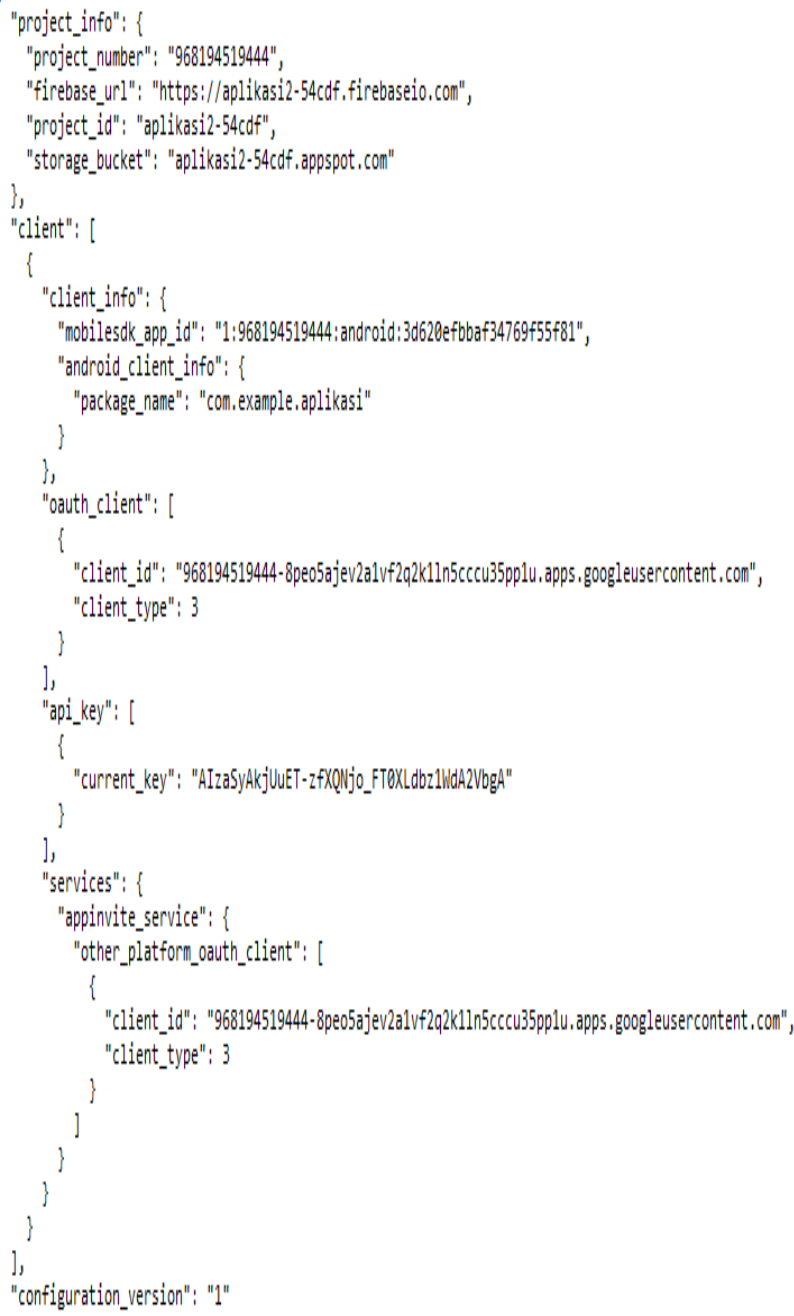

\subsection{Database Design}

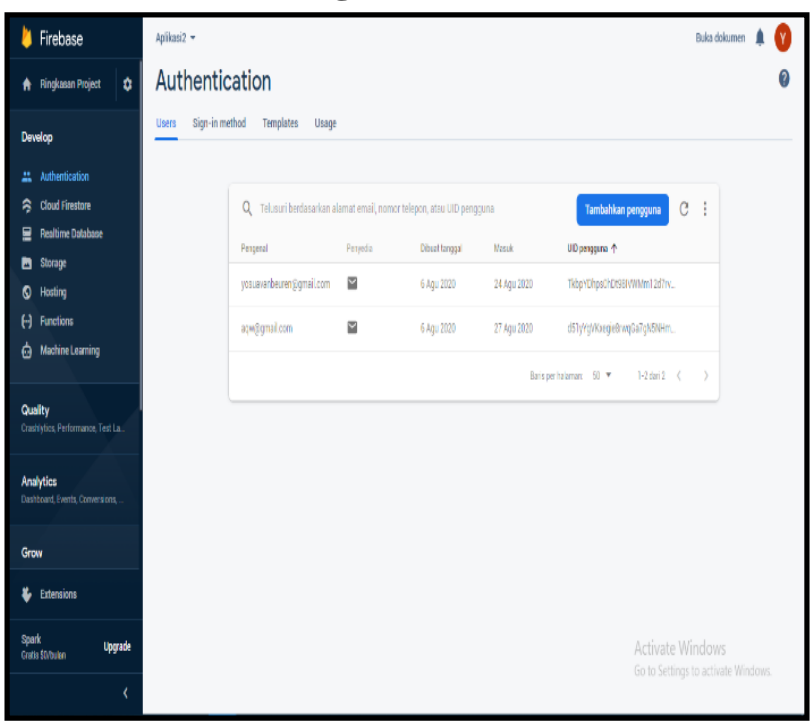

Fig 7: Realtime database login in firebase 


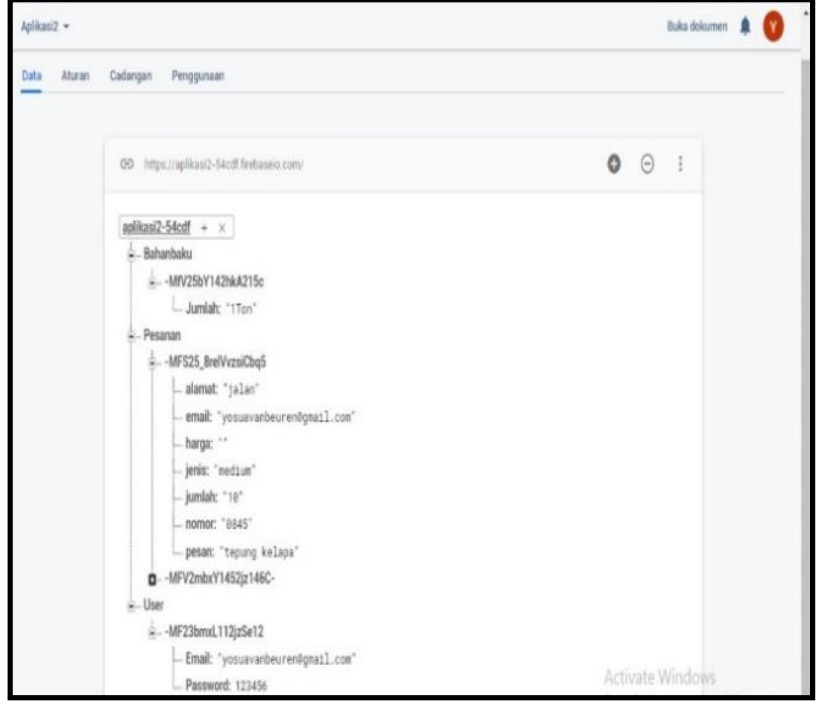

Fig 8: Realtime database order in firebase

Database implementation using firebase which is implemented without using Sql or No Sql makes a process for the data to be distributed through firebase which is stored in JavaScript Object Notation (JSON) which allows data synchronization from both sides of the consumer who will order. coconut flour products, receive notifications and invoices and on the admin side who will receive orders from consumers, the data will always be updated when there is new data so that communications and transactions can run effectively and efficiently.

\section{CONCLUSION}

The design in this study which implements a real-time database using firebase, provides a different approach because the platform offered is a cloud so that the development process becomes easier on the client or user side.

The synchronization process on firebase allows transaction data or communication between consumers and manufacturers to be sent in real-time.

\section{ACKNOWLEDGMENTS}

Thank you to the Ministry of Research and Technology of the Republic of Indonesia and the leadership of Manado State Polytechnic for the opportunity to conduct this research.

\section{REFERENCES}

[1] H. Kapoh, O. Melo, A. A. Kimbal and A. Polii, "Model Transaction of Raw Material for Coconut Fruit On North Sulawesi Coconut Flour Industry," 2018 International Conference on Applied Science and Technology (iCAST), Manado, Indonesia, 2018, pp. 200-204.

[2] Kapoh, Harson, Edwin Stephanus Lumunon, and Olga Melo. "Material Requirement Model of Coconut Flour Production and Performance Testing based Multi User in North Sulawesi." International Journal of Computer Applications 152.7.2016

[3] K. M. Hlaing and D. E. Nyaung, "Electricity Billing System using Ethereum and Firebase," 2019 International Conference on Advanced Information Technologies (ICAIT), Yangon, Myanmar, 2019, pp. 217-221, doi: 10.1109/AITC.2019.8920931.

[4] W. Li, C. Yen, Y. Lin, S. Tung and S. Huang, "JustIoT Internet of Things based on the Firebase real-time database," 2018 IEEE International Conference on Smart Manufacturing, Industrial \& Logistics Engineering (SMILE), Hsinchu, 2018, pp. 43-47, doi: 10.1109/SMILE.2018.8353979. 